\title{
Maintaining balance: what (dis)qualifies a nonaffiliated IACUC candidate?
}

\author{
G \\ reat Eastern University was recruiting \\ a nonaffiliated member for its \\ IACUC. The committee chairman, \\ Dr. Larry Covelli, was not sure about a \\ recommendation to add recently retired \\ U.S. senator Jonathan Blackburn. The \\ colleague who recommended Blackburn \\ had asked him if he was interested, and \\ Blackburn responded that he would be \\ delighted to join the IACUC. The problem \\ was that Blackburn had introduced many \\ bills to limit or even eliminate the use of \\ animals in biomedical research. Covelli \\ discussed the nomination with the full \\ committee to see if the members would \\ like him to ask the Institutional Official to \\ appoint Blackburn to the committee. \\ The initial response from many members \\ of the IACUC was that it would be a mistake \\ to have a member who clearly opposed \\ biomedical research that used animals. \\ "He's going to vote against approving every \\ protocol that comes before him," was the \\ typical comment. "I had the same concern \\ at first," said Covelli, "but then I thought, \\ why would a smart guy like Blackburn want \\ to join a committee where he knows that \\ the basic premise is to approve worthwhile \\ research with animals if it follows the
}

U.S. Government Principles ${ }^{1}$ and complies with all pertinent regulations? So, my guess is that he won't be a fly in the ointment, but he'll be a counterbalance to committee members who might miss certain weaknesses in a protocol. He might even be an asset rather than a drawback to our program."

"On the other hand," commented an IACUC member, "he can slow down the work of this committee to a crawl or give out confidential research information to his buddies in the senate who are still set to oppose our work." Covelli said that was always possible, but he would have to sign and abide by the same confidentiality agreement that everybody else on the committee signs. And, Covelli added, there was always a chance that any committee member could steal an idea from another committee member's research.

The director of the IACUC office said she heard that Blackburn is still very involved in community activities and has his finger on the pulse of community sentiments. She said she would be in favor of adding him, because he has no history of ever using animals in research, he is conversant with the use of laboratory animals, he has had no affiliation with the school, and as far as she knew, he has no relatives who are affiliated with the school. She said, "at least on the surface, he seems like a good fit for the IACUC. I like the idea of having an unaffiliated member who knows about research, is interested in animal welfare, who can truly represent the community, and would not be afraid to take a position that differs from most of us on the IACUC. At the very least, can't we invite him in for an interview and question him about being on the committee?"

What is your opinion about adding Blackburn to the Great Eastern IACUC and how would you proceed if you were chairing the meeting?

\section{Jerald Silverman \\ University of Massachusetts Medical School, \\ Worcester, Massachusetts, USA. \\ e-mail: Jerald.Silverman@umassmed.edu}

Published online: 21 May 2019

https://doi.org/10.1038/s41684-019-0306-x

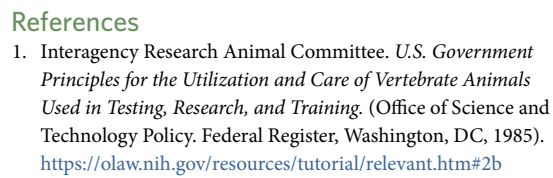

\section{Granting IACUC membership to Blackburn with caution can benefit the committee}

\footnotetext{
$\mathrm{T}$ he committee raised valid concerns with allowing Blackburn to become part of the IACUC as their nonaffiliated member. With Blackburn's history of sponsoring proposed bills to limit or eliminate the use of animals in laboratory research, it is fair for the committee to express apprehensions about whether there will be demonstrable bias in his opinions about animal-based research if he were to become a member. In addition, there is potential that he may delay protocol approvals by asking more questions or clarifications on the use of animals, even though he cannot individually block a given protocol when the majority of the committee members vote in favor of it. With that said,
}

he may meet the criteria to be a nonaffiliated member. He clearly knows that animals are used in biomedical research but has not used them himself, and he is not affiliated with the school. It also appears that he does not have any immediate family such as a parent, spouse, child or sibling affiliated with the institution, as defined in the OLAW guidelines ${ }^{1}$. This of course requires confirmation before the final decision is made to appoint him as a nonaffiliated member.

It is important to understand the circumstances that compelled Blackburn to propose bills against animal use in research. Valid questions to contemplate include: Is he part of an animal activist group?
Did he oppose using a specific species of animal? Were there any adverse incidents with animal research that influenced him to file bills against animal use? Blackburn might have been opposed to animal use due to reasonable concerns related to a single institution or specific studies. Given his willingness to participate in the IACUC, his views may have changed with additional education on the care of lab animals and through review of in vivo research.

A person with no experience working within the laboratory animal field brings significant value to the IACUC, where the nonaffiliated member's purpose is to help represent the views and concerns within the community. Even with the concerns that 